\title{
A Comparison of Physical Soil Organic Matter Fractionation Methods for Amended Soils
}

\author{
Sarah Duddigan $\left(\mathbb{D},{ }^{1}\right.$ Liz J. Shaw ${ }^{D},{ }^{1}$ Paul D. Alexander, ${ }^{2}$ and Chris D. Collins ${ }^{1}$ \\ ${ }^{1}$ Department of Geography and Environmental Science, University of Reading, Reading, UK \\ ${ }^{2}$ Royal Horticultural Society, Wisley, UK \\ Correspondence should be addressed to Sarah Duddigan; s.duddigan@reading.ac.uk
}

Received 12 July 2019; Accepted 5 October 2019; Published 11 November 2019

Academic Editor: Teodoro M. Miano

Copyright (C) 2019 Sarah Duddigan et al. This is an open access article distributed under the Creative Commons Attribution License, which permits unrestricted use, distribution, and reproduction in any medium, provided the original work is properly cited.

\begin{abstract}
Selecting a suitable physical fractionation method, to investigate soil organic matter dynamics, from the plethora that are available is a difficult task. Using five different physical fractionation methods, on soils either nontreated or with a history of amendment with a range of exogenous organic matter inputs (Irish moss peat; composted horse manure; garden compost) and a resulting range of carbon contents (6.8 to $22.2 \%$ ), we show that method selection had a significant impact on both the total C recovered and the distribution of the recovered $\mathrm{C}$ between unprotected, physically protected, or chemically protected conceptual pools. These between-method differences most likely resulted from the following: (i) variation in the methodological fractions obtained (i.e., distinguishing between aggregate size classes); (ii) their subsequent designation to conceptual pools (e.g., protected versus unprotected); and (iii) the procedures used in sample pretreatment and subsequent aggregate dispersion and fractionation steps. The performance of each method also varied depending on the amendment in question. The findings emphasise the need for an understanding of the nature of the soil samples under investigation, and the stabilisation mechanism of interest, both prior to method selection and when comparing and interpreting findings from literature studies using different fractionation methods.
\end{abstract}

\section{Introduction}

Soil organic carbon (SOC) is one of the most important indicators of soil quality [1]. Soils contain approximately three times more carbon than the atmosphere or terrestrial vegetation [2], accounting for $80 \%$ of the terrestrial carbon pool [3]. Therefore, maintenance and enhancement of soil carbon stocks is of great importance when considering both the promotion of soil health and the regulation of the global carbon cycle, a fact recognised during the $21^{\text {st }}$ Conference of the Parties to the United Nations Framework Convention on Climate Change (COP21) in Paris, 2015, where the "4 per mille Soils for Food Security and Climate" action agenda was developed [4].

The application of organic soil amendments in horticultural systems, such as manure and composts (i.e., green waste compost and spent mushroom compost), has been reported to increase SOC [5-7]. However, in order to inform future management strategies that aim to enhance
SOC storage, it is vital that research establishes which mechanisms are dominant in organic $\mathrm{C}$ stabilization in soils [8].

There has been a traditional view, regularly reported in the literature [8-13], that there are three key stabilisation mechanisms that can protect SOC contained within soil organic matter (SOM) from being decomposed and mineralised in soils: (i) Biochemical stabilisation, relating to the presence and selective preservation of molecules resistant to decomposition as a result of their chemical structure. This recalcitrance may be either intrinsic to initial structure, or created as a result of the formation of chemically complex structures through condensation and secondary synthesis reactions. (ii) Physical stabilisation, relating to the occlusion of SOM within aggregates, causing physical disconnection and therefore inaccessibility of SOM to decomposer microorganisms. (iii) Chemical stabilisation, whereby SOM becomes chemically inaccessible to decomposers as a result of sorption of SOM onto mineral surfaces and complexation with metal ions. 
Historically, it was thought that SOM persistence was mostly a function of biochemical stabilisation [11]. However, more recent synthesis of evidence questions the importance of selective preservation of structures traditionally thought to be inherently recalcitrant (e.g., lignin) and also the importance of structures with acquired biochemical recalcitrance via secondary synthesis ("humification") in the control of SOC persistence [2]. Instead, the consensus now supports the fact that physical stabilisation through occlusion and chemical stabilisation via sorption and complexation are the dominant mechanisms controlling the longterm persistence of SOC [2].

Soil physical fractionation methods have been adopted to quantify the amount of $\mathrm{C}$ associated with pools of different theoretical stability, and how these $\mathrm{C}$ pools are affected by various management techniques, including the addition of organic amendments [7, 12]. These fractionation methods typically quantify SOC that is (i) contained within aggregates and therefore, in theory, physically protected through occlusion; (ii) complexed within organomineral associations and therefore chemically protected; or (iii) unprotected (free) and therefore accessible to microorganisms, and their enzymes, for decomposition. These methods can be informative about the stability of SOM in the soil system [10] and the sensitivity of SOM dynamics to change [14]. In addition, physical fractionation can increase understanding and prediction of SOC dynamics if procedures can produce fractions that are translatable to pools in soil carbon models [15]. However, the plethora of physical fractionation methods available in the literature makes it difficult to select an appropriate and informative method. Furthermore, it is likely that the suitability of a particular method, and therefore appropriate method selection, will depend on soil management history. Recent fractionation comparisons [16] have focussed on arable soils with SOC contents (1-2\%) typical of such systems that are ploughed, NPK fertilized, and receive no $\mathrm{OM}$ amendment other than crop residues (maize) or no inputs/tillage at all (miscanthus). It is uncertain whether conclusions from method intercomparisons done in arable soils are applicable to soils receiving annual exogenous OM amendments, such as those in horticultural systems, and likely differing in both total SOC content and the distribution of SOC between physical fractions.

The aim of this study was therefore to trial five published physical fractionation methods in soil receiving horticultural $\mathrm{OM}$ amendments, with particular interest in comparing the distribution of $\mathrm{C}$ among fractions defined as physically protected, chemically protected, or unprotected as reported by each method. An additional objective was to evaluate the logistical ease of conducting each method in the laboratory. To the best of our knowledge, this is the most extensive comparison of physical fractionation methods to be conducted within the same laboratory, by the same operator, for soils receiving exogenous organic matter inputs.

\section{Methods}

2.1. Site Description and Soil Sampling. Soil samples (0$15 \mathrm{~cm}$ depth) were taken in October 2013 from the Royal
Horticultural Society's (RHS) Deer Farm in Wisley, UK $\left(51.323428^{\circ} \mathrm{N},-0.474392^{\circ} \mathrm{W}\right)$, details of which can be found in the study by Alexander and Nevison [17]. The site consisted of a sandy loam soil that had received annual applications for 6 years of either: Irish moss peat (Pt); composted horse manure $(\mathrm{H})$; or garden compost at full rate (GCf) and half rate (GCh) from collected prunings and cuttings from RHS Wisley Garden, UK. Prior to sampling (May 2013), the plots had been sown with Phacelia tanacetifolia Bentham, with above ground material harvested and removed in September 2013. The amendments were applied annually in early spring as a $5 \mathrm{~cm}$ layer on the surface of the soil (with the exception of the GCh treatment which received $2.5 \mathrm{~cm}$ ), and incorporated into the top $15 \mathrm{~cm}$ of soil with the use of a rotovator. Soil from an unamended, bare plot control (BP) was also collected. These different organic matter amendments resulted in a range of total $\mathrm{C}$ contents across the treatments (Table 1).

The different soil amendment treatments, on a single soil type, have been selected solely to provide a suite of $\mathrm{C}$ contents to test the different physical fractionation methods whilst avoiding the ambiguity of the use of multiple soil types with various textures etc.

Bulk soils of each treatment were sampled by auger from 0 to $15 \mathrm{~cm}$. A sample splitter was used to obtain 15 representative subsamples of each soil (3 replicate samples for each fractionation method). Samples were further prepared (i.e., dried and sieved) according to the requirements of each individual method (Table 2).

2.2. Organic Matter Fractionation. Soil subsamples were subjected to the five fractionation procedures according to the following published methods: (i) Plaza et al. [18] using a microaggregate isolator, sonication, and density flotation (PL); (ii) Six et al. [9] using size separation, a microaggregate isolator, and density floatation (SD); (iii) Six et al. [9] using size separation, a microaggregate isolator, and sodium hexametaphosphate (NaHMP) for dispersion (SMI); (iv) Sohi et al. [19] using sonication and density floatation (SO); and (v) Zimmermann et al. [15] using size separation and density flotation (ZM). Each of the methods will be referred to by the stated abbreviations from this point forward. A brief overview of key features of each method can be found in Table 2. All organic matter fractionation methods were conducted in the same laboratory, by the same operator.

The methods differ in the number and description of the physical fractions that they obtain. An overview of these methods with fractions categorised by conceptual pool as: (i) physically protected (in aggregates, particularly microaggregates); (ii) chemically protected (through mineral association); or (iii) unprotected by chemical or physical mechanisms (free particulate organic matter), is given in Table 3.

The categorisation in Table 3 is somewhat subjective since some methods ( $\mathrm{SO}$ and $\mathrm{ZM}$ ) designate SOM occluded in microaggregates and macroaggregates as physically 
TABle 1: C content of whole (not sieved) soils used for the fractionation trials.

\begin{tabular}{|c|c|c|}
\hline Treatment & Abbreviation & $\begin{array}{l}\text { Whole soil C } \\
\left(\mathrm{mg} \mathrm{C}^{-1} \mathrm{~g}^{-1}\right)\end{array}$ \\
\hline Nonamended bare plot control & $\mathrm{BP}$ & $68.22 \pm 2.23^{\mathrm{e}}$ \\
\hline Garden compost (full rate) & GCf & $112.28 \pm 5.66^{\mathrm{c}}$ \\
\hline Garden compost (half rate) & GCh & $81.67 \pm 7.98^{\mathrm{d}}$ \\
\hline Composted horse manure & $\mathrm{H}$ & $145.86 \pm 3.81^{\mathrm{b}}$ \\
\hline Peat & $\mathrm{Pt}$ & $222.40 \pm 1.64^{\mathrm{a}}$ \\
\hline
\end{tabular}

Data are mean \pm standard deviation $(n=3)$. Mean values not sharing a superscript letter are significantly different $(p<0.05$; Tukey's significant difference).

protected but others (SD and SMI) only consider OM occluded in microaggregates as physically protected. These differing descriptions between methods have been accommodated in Table 3 as follows: methods that define microaggregates as a fraction have had the $\mathrm{OM}$ in this fraction categorised as physically protected and macroaggregate $\mathrm{OM}$ as unprotected. Methods that do not distinguish between microaggregates and macroaggregates, and pool them as one aggregate fraction, have had the whole aggregate fraction classified as physically protected.

In addition, some of the methods use different size classes during sieving, which may result in overlaps over different conceptual pools. The ZM method, for example, classes $\mathrm{OM}$ that is $<63 \mu \mathrm{m}$ as chemically protected, whereas SD and SMI uses $<53 \mu \mathrm{m}$ sieves. Therefore, the 53-63 $\mu \mathrm{m}$ fraction of $\mathrm{OM}$ obtained may contain unprotected $\mathrm{OM}$, chemically protected $\mathrm{OM}$, and physically protected $\mathrm{OM}$ depending on the method used. Thus, it is uncertain which method is most efficient at separating physically protected OM from chemical protection.

It should also be noted that that the nomenclature assigned to each of the fractions in Table 3 are the names used in the original publications. Therefore, due to betweenpublication differences in nomenclature, fractions that are identical, or very similar, may have different names. For example, free particulate OM (that is not protected by physical or chemical mechanisms) is defined as particulate $\mathrm{OM}$, or POM, in the ZM method, free OM (fOM) in the PL method, or the free light fraction (FLF) in the SO method.

Of the methods tested, only two, PL and ZM, define dissolved organic matter (DOM) as a fraction. However, the ZM method required such a large volume of water to wash out DOM that, in this case, the concentrations were too low to detect on a Shimadzu TOC analyser. The low concentration of DOM in these samples (mean $3.6 \mathrm{mg} \mathrm{C} \mathrm{g.soil}{ }^{-1}$ ) recovered in the PL method meant that its contribution was negligible to total $\mathrm{C}$ recovery in this trial. Therefore, in the interest of simplifying comparisons between methods, DOM was excluded from analysis.

2.3. Chemical Analyses. All fractions obtained were dried at the temperature stated in the corresponding published method. Samples were ground to $0.2 \mathrm{~mm}$ using a TEMA disc mill and analysed for total $\mathrm{C}$ content on a Thermo Scientific Flash $2000 \mathrm{CHNS} / \mathrm{O}$ analyser.
Resulting data were expressed as the amount of physically protected, chemically protected, and unprotected C as $\mathrm{mg} \mathrm{C} \mathrm{g \cdot soil}{ }^{-1}$. In addition, in order to account for different total $\mathrm{C}$ recoveries, the amount of aggregate $\mathrm{C}$ and free $\mathrm{POM}$ $\mathrm{C}$ obtained using each method was also expressed as a percentage of the total $\mathrm{C}$ recovered in each method.

Finally, in order to assess the quality of the fractions obtained (and therefore their suitability for further analysis), the $\mathrm{C}$ concentration of the fractions expressed as $\mathrm{mg} \mathrm{C}$ g.fraction ${ }^{-1}$ was also calculated. This allows us to review the effects of mineral components, in particular sand, in the different fractions of each method.

2.4. Statistical Analysis. All statistical analyses were conducted using Minitab (18.0). Once tested for normality (Anderson-Darling test) and equal variance (Levene's test), two-way analysis of variance (ANOVA), with interactions, was conducted using fractionation method (PL, SD, SMI, $\mathrm{SO}$, or ZM) and soil treatment (BP, GCf, GCh, H, or Pt) as factors. Tukey's honest significant difference test was used for post hoc comparison of means. In the case where data are represented as a percentage (e.g., \% recovery), all the data were arcsine transformed before normality and homogeneity of variance testing, and subsequent two-way ANOVA.

As this is a methods comparison, discussing the effects of amendment application on $\mathrm{C}$ dynamics is not within the scope of this research. Therefore, the results presented and discussed here will focus on the effect of fractionation method and interactions, rather than the effect of amendment treatment alone on different conceptual C pools.

\section{Results}

3.1. Total C Recovery. The physical fractionation method used in this trial had a significant impact on how much $\mathrm{C}$ of total soil $\mathrm{C}$ could be recovered during the fractionation process $(p<0.05$; Table 4$)$. The SMI and SO methods recovered more $\mathrm{C}$ in total than the other three methods (PL, $\mathrm{SD}$, and $\mathrm{ZM}$ ). The bare plot control treatment, which as the unamended soil has the lowest total C content (Table 1), had a higher recovery than the peat soil, which had the highest $\mathrm{C}$ content due to amendment. There were no other significant differences between treatment; however, there were significant interactions between method and treatment $(p<0.05)$. For example, total $\mathrm{C}$ recovery for horse manure-treated soil was the lowest for four out of the five methods (PL, SD, SO, and $\mathrm{ZM}$ ) but was the highest when using the SMI method (Table 4).

3.2. Unprotected C Recovery. Figure 1(a) shows that the PL and SMI recovered more unprotected $C(p<0.05)$ than the other three methods (SD, SO, and $\mathrm{ZM}$ ) but the effect of method on recovery depended on OM treatment $(p<0.05)$. For example, recovery of unprotected $\mathrm{C}$ in horse manureamended soil was particularly high when using the SMI method and, when using the PL method, unprotected C recovery in peat-amended soil was high. 
TABle 2: Overview of physical fractionation methods.

\begin{tabular}{|c|c|c|c|c|c|}
\hline \multicolumn{6}{|c|}{ Physical fractionation method } \\
\hline & $\begin{array}{l}\text { Plaza et al. [18] } \\
\text { (PL) }\end{array}$ & $\begin{array}{l}\text { Six et al. [9] density } \\
\text { (SD) }\end{array}$ & $\begin{array}{c}\text { Six et al. [9] } \\
\text { microaggregate isolator } \\
\text { (SMI) }\end{array}$ & $\begin{array}{l}\text { Sohi et al. [19] } \\
\text { (SO) }\end{array}$ & $\begin{array}{l}\text { Zimmermann et al. [15] } \\
\text { (ZM) }\end{array}$ \\
\hline Sample prep & $\begin{array}{l}\text { Soil air-dried and sieved } \\
\qquad(<2 \mathrm{~mm})\end{array}$ & $\begin{array}{l}\text { Air-dried soil } \\
\text { not sieved }\end{array}$ & $\begin{array}{l}\text { Air-dried soil not } \\
\text { sieved }\end{array}$ & $\begin{array}{l}\text { Field fresh } \\
\text { soils not } \\
\text { sieved }\end{array}$ & $\begin{array}{l}\text { Soil air-dried and sieved } \\
\qquad(<2 \mathrm{~mm})\end{array}$ \\
\hline \multirow{6}{*}{$\begin{array}{l}\text { Initial size } \\
\text { fractionation }\end{array}$} & & $\begin{array}{l}\text { Wet sieved into four size } \\
\text { classes: }\end{array}$ & $\begin{array}{c}\text { Wet sieved into four size } \\
\text { classes: }\end{array}$ & & $\begin{array}{l}\text { Lightly sonicated at } \\
22 \mathrm{~J} \cdot \mathrm{ml}^{-1} \text { then wet sieved } \\
\text { into two size classes: }\end{array}$ \\
\hline & & $\begin{array}{l}\text { Large macroaggregates } \\
\qquad(>2000 \mu \mathrm{m})\end{array}$ & $\begin{array}{l}\text { Large macroaggregates } \\
\qquad(>2000 \mu \mathrm{m})\end{array}$ & & $\begin{array}{l}\text { Intra-aggregate, free } \\
\text { POM, and sand } \\
\text { associated }(>63 \mu \mathrm{m})\end{array}$ \\
\hline & & Small macroaggregates & Small macroaggregates & & \multirow{4}{*}{$\begin{array}{l}\text { Dissolved, clay and silt } \\
\text { associated }(<63 \mu \mathrm{m})\end{array}$} \\
\hline & & $(250-2000 \mu \mathrm{m})$ & $(250-2000 \mu \mathrm{m})$ & & \\
\hline & & $\begin{array}{l}\text { Microaggregates } \\
(53-250 \mu \mathrm{m})\end{array}$ & $\begin{array}{l}\text { Microaggregates } \\
\quad(53-250 \mu \mathrm{m})\end{array}$ & & \\
\hline & & Silt and clay $(<53 \mu \mathrm{m})$ & Silt and clay $(<53 \mu \mathrm{m})$ & & \\
\hline $\begin{array}{l}\text { Density fluid } \\
\text { used }\end{array}$ & SPT $1.85 \mathrm{~g} \cdot \mathrm{cm}^{-3}$ & SPT $1.85 \mathrm{~g} \cdot \mathrm{cm}^{-3}$ & None & $\begin{array}{c}\mathrm{NaI} 1.80 \\
\mathrm{~g} \cdot \mathrm{cm}^{-3}\end{array}$ & SPT $1.80 \mathrm{~g} \cdot \mathrm{cm}^{-3}$ \\
\hline $\begin{array}{l}\text { Aggregate } \\
\text { classes }\end{array}$ & $\begin{array}{l}\text { Distinguishes between } \\
\text { macroaggregates } \\
(250-2000 \mu \mathrm{m}) \text { and } \\
\text { microaggregates } \\
(<250 \mu \mathrm{m})\end{array}$ & $\begin{array}{l}\text { Distinguishes between } \\
\text { large macroaggregates } \\
(>2000 \mu \mathrm{m}), \text { small } \\
\text { macroaggregates } \\
(250-2000 \mu \mathrm{m}), \text { and } \\
\text { microaggregates } \\
(53-250 \mu \mathrm{m})\end{array}$ & $\begin{array}{l}\text { Distinguishes between } \\
\text { large macroaggregates } \\
(>2000 \mu \mathrm{m}), \text { small } \\
\text { macroaggregates } \\
(250-2000 \mu \mathrm{m}), \\
\text { microaggregates } \\
(53-250 \mu \mathrm{m}), \text { and } \\
\text { microaggregates } \\
\text { contained within } \\
\text { macroaggregates }\end{array}$ & $\begin{array}{l}\text { All aggregates } \\
\text { in one } \\
\text { fraction }\end{array}$ & $\begin{array}{l}\text { All aggregates in one } \\
\text { fraction }\end{array}$ \\
\hline \multirow[t]{2}{*}{$\begin{array}{l}\text { Aggregate } \\
\text { dispersion } \\
\text { method }\end{array}$} & $\begin{array}{l}\text { Macroaggregates use a } \\
\text { microaggregate isolator } \\
\text { (breaks up } \\
\text { macroaggregates whilst } \\
\text { keeping microaggregates } \\
\text { contained within intact) }\end{array}$ & $\begin{array}{l}\text { Placed under a vacuum } \\
\qquad(138 \mathrm{kPa})\end{array}$ & $\begin{array}{c}\text { Macroaggregates use a } \\
\text { microaggregate isolator } \\
\text { (breaks up } \\
\text { macroaggregates whilst } \\
\text { keeping the } \\
\text { microaggregates } \\
\text { contained within intact) }\end{array}$ & $\begin{array}{l}\text { Sonication at } \\
1500 \mathrm{~J} \cdot \mathrm{g}^{-1}\end{array}$ & \multirow[t]{2}{*}{ None } \\
\hline & $\begin{array}{c}\text { Microaggregates: } \\
\text { sonication at } 1500 \mathrm{~J} \cdot \mathrm{g}^{-1}\end{array}$ & & $\begin{array}{l}\text { Microaggregates: } 0.5 \% \\
\text { NaHMP to disperse }\end{array}$ & & \\
\hline $\begin{array}{l}\text { Mineral } \\
\text { fraction }\end{array}$ & Sand, silt, and clay & Sand, silt, and clay & $\begin{array}{l}\text { Silt and clay (sand } \\
\text { makes up part of the } \\
\text { aggregate fractions) }\end{array}$ & $\begin{array}{l}\text { Sand, silt, and } \\
\text { clay }\end{array}$ & $\begin{array}{l}\text { Silt and clay (sand } \\
\text { makes up part of the } \\
\text { aggregate fractions) }\end{array}$ \\
\hline
\end{tabular}

Three of the five methods (PL, SO, and ZM) involve initial separation of free POM, not associated with aggregates or mineral components, using density flotation. The SD and SMI methods do not have an initial separation of free POM before aggregate dispersion; so, it is difficult to distinguish between intra-aggregate $\mathrm{OM}$ and free particulate $\mathrm{OM}$ of the same aggregate size class (discussed later) and decipher how they compare to the other methods with regard to the isolation of free POM. Examining those methods that did distinguish a free POM fraction revealed a significant effect of method $(p<0.05)$ on $C$ recovery in free POM (Table 5) with the PL method recovering the most free POM C, followed by ZM and SO. However, free POM C recovery for a given method depended on OM treatment, as evidenced by a significant method $*$ treatment interaction $(p<0.05)$. For example, PL and ZM methods recovered more
POM C in the full-rate garden compost treatment than the half-rate treatment but the SO method recovered similar amount of POM C for both (Table 5). In addition, POM recovery in the horse manure treatment was among the lowest in the SO method, but one of the highest for the PL and ZM methods (Table 5).

3.3. Physically Protected C Recovery. Fractionation method had an overall significant effect on recovery of physically protected C $(p<0.05$; Figure $1(\mathrm{~b}))$. The SMI, SO, and ZM isolated significantly more physically protected $\mathrm{C}$ than the SD and PL method, with the PL method isolating the least physically protected C. Again, there were significant method $\times$ treatment interactions $(p<0.05)$ according to two-way ANOVA. For example, the SO method isolated the 
TABLE 3: Fractions obtained in each method as categorised by stabilisation mechanism: physically protected, chemically protected, or unprotected OM. Nomeclature provided by the original publications.

\begin{tabular}{|c|c|c|c|c|c|}
\hline \multicolumn{6}{|c|}{ Physical fractionation method } \\
\hline $\begin{array}{l}\text { Stabilisation } \\
\text { mechanism }\end{array}$ & Plaza et al. [18] (PL) & Six et al. [9] density (SD) & $\begin{array}{c}\text { Six et al. [9] } \\
\text { microaggregate isolator } \\
\text { (SMI) }\end{array}$ & $\begin{array}{l}\text { Sohi et al. [19] } \\
\text { (SO) }\end{array}$ & $\begin{array}{l}\text { Zimmermann } \\
\text { et al. [15] (ZM) }\end{array}$ \\
\hline Unprotected & $\begin{array}{l}\text { (i) Free OM (fOM) } \\
\text { (ii) Intramacroaggregate } \\
\text { OM (i-MaOM) } \\
\text { (iii) Dissolved OM } \\
\text { (DOM) }\end{array}$ & $\begin{array}{l}\text { (i) Free POM within large } \\
\text { and small macroaggregates } \\
\text { (lM fPOM and sM fPOM) }\end{array}$ & $\begin{array}{c}\text { (i) Large POM/Litter } \\
>2000 \mu \mathrm{m}(>2000 \mathrm{POM}) \\
\text { (ii) Coarse POM in large } \\
\text { and small } \\
\text { macroaggregates (1M } \\
\text { cPOM and sM cPOM) }\end{array}$ & $\begin{array}{l}\text { (i) Free light OM } \\
\text { (FLF) }\end{array}$ & $\begin{array}{c}\text { (i) Particulate } \\
\text { organic matter } \\
\text { (POM) } \\
\text { (ii) Dissolved } \\
\text { organic C (DOC) }\end{array}$ \\
\hline Physical & $\begin{array}{l}\text { (i) Intramicroaggregate } \\
\text { OM (i-miOM) }\end{array}$ & $\begin{array}{c}\text { (i) Free POM within } \\
\text { microaggregates (m fPOM) } \\
\text { (ii) Free POM in } \\
\text { microaggregates within large } \\
\text { and small macroaggregates } \\
\text { (mlM fPOM and msM } \\
\text { fPOM) }\end{array}$ & $\begin{array}{l}\text { (i) Intramicroaggregate } \\
\text { POM (imPOM) } \\
\text { (ii) Intramicroaggregate } \\
\text { POM within large and } \\
\text { small macroaggregates } \\
\text { (imlM POM and imsM } \\
\text { POM) }\end{array}$ & $\begin{array}{l}\text { (i) Intraaggregate } \\
\text { light OM (iAFLF) }\end{array}$ & $\begin{array}{l}\text { (i) Sand and stable } \\
\text { aggregates }(S+A)\end{array}$ \\
\hline Chemical & $\begin{array}{l}\text { (i) Mineral-associated } \\
\text { (MinOM) }\end{array}$ & $\begin{array}{l}\text { (i) Mineral-associated SOC } \\
\text { within large and small } \\
\text { macroaggregates (IM mSOC } \\
\text { and sM mSOC) } \\
\text { (ii) Mineral-associated SOC } \\
\text { within microaggregates (m } \\
\text { mSOC) } \\
\text { (iii) Silt and clay }(s+c)\end{array}$ & $\begin{array}{l}\text { (i) Silt and clay }(s+c) \\
\text { (ii) Silt and clay within } \\
\text { large and small } \\
\text { macroaggregates }(\mathrm{lM} s+c \\
\text { and sM } s+c) \\
\text { (iii) Silt and clay within } \\
\text { microaggregates }(\mathrm{m} s+c)\end{array}$ & $\begin{array}{l}\text { (i) Mineral- } \\
\text { associated OM } \\
\text { (MA) }\end{array}$ & $\begin{array}{l}\text { (ii) Resistant soil } \\
\text { organic C (rSOC) }\end{array}$ \\
\hline
\end{tabular}

TABLE 4: Total C recovery of fractionation method for amended soil.

\begin{tabular}{lcccccr}
\hline \multirow{2}{*}{ Treatment } & \multicolumn{5}{c}{ Method } \\
& PL & SD & SMI & SO & ZM & Mean of treatment $(n=15)$ \\
\hline BP & $60.3 \pm 2.2$ & $67.4 \pm 5.6$ & $101.8 \pm 8.3$ & $75.8 \pm 3.7$ & $53.0 \pm 1.1$ & $\mathbf{7 1 . 7} \pm \mathbf{4 . 9 A}$ \\
GCf & $69.2 \pm 0.7$ & $65.1 \pm 0.6$ & $70.1 \pm 3.3$ & $85.5 \pm 1.9$ & $66.3 \pm 0.9$ & $\mathbf{7 1 . 2} \pm \mathbf{2 . 1 A B}$ \\
GCh & $74.6 \pm 1.5$ & $63.9 \pm 1.6$ & $64.5 \pm 1.5$ & $74.3 \pm 10.3$ & $72.2 \pm 5.9$ & $\mathbf{6 9 . 9} \pm 2.4 A B$ \\
H & $54.3 \pm 1.3$ & $44.3 \pm 5.3$ & $127.3 \pm 17.2$ & $63.7 \pm 1.2$ & $47.8 \pm 1.9$ & $\mathbf{6 7 . 5} \pm \mathbf{8 . 7 A B}$ \\
Pt & $70.8 \pm 1.2$ & $51.3 \pm 0.5$ & $51.4 \pm 1.8$ & $77.8 \pm 8.1$ & $61.9 \pm 6.4$ & $\mathbf{6 2 . 6} \pm \mathbf{3 . 3 B}$ \\
Mean of method $(\boldsymbol{n = 1 5 )}$ & $\mathbf{6 5 . 8} \pm \mathbf{2 . 1 b}$ & $\mathbf{5 8 . 4 1} \pm \mathbf{2 . 8 b}$ & $\mathbf{8 3 . 0 1} \pm \mathbf{8 . 1 a}$ & $\mathbf{7 5 . 4} \pm \mathbf{3 . 0 a}$ & $\mathbf{6 0 . 2 4} \pm \mathbf{2 . 8 b}$ & \\
\hline
\end{tabular}

Values are expressed as a percentage of whole, unsieved, soil C (shown in Table 1). Mean \pm standard error $(n=3)$. Lowercase letters in the bold values signify methods that are not significantly different, and uppercase letters signify treatments that are not significantly different according to two-way ANOVA with Tukey's post hoc testing $(p>0.05)$. Method $*$ treatment interactions $(p<0.01)$.

most physically protected $\mathrm{C}$ in the peat and garden compost (both full and half rate) amended soil but did not for the bare plot control or the horse manure amended soil.

3.3.1. Aggregate C. As mentioned previously, some methods (PL, SD, and SMI) distinguish between microaggregate and macroaggregate $\mathrm{C}$, and designate them as physically protected and unprotected, respectively. The SO and ZM methods, however, group all aggregate OM together. Examining how much total aggregate $C$ was isolated by each method, regardless of size class (Table 6), revealed that fractionation method had an overall significant effect $(p<0.05)$. Post hoc analysis showed that the SD and SMI methods recovered significantly more aggregate $C$ than the other three methods and the SO method recovered significantly more aggregate $C$ than the PL method with recovery for the ZM in between the two (Table 6). However, there were significant method $\times$ treatment interactions $(p<0.05)$. For example, out of the OM treatments, aggregate $\mathrm{C}$ recovery was amongst the highest for horse manure for the SD method but the lowest for the SO method.

3.4. Chemically Protected C Recovery. Fractionation method had an overall significant effect on chemically protected $\mathrm{C}$ recovery $(p<0.05$; Figure $1(c))$. The SO method recovered significantly more chemically protected $C$ than all other methods, and the PL recovered the least. Once again, however, 


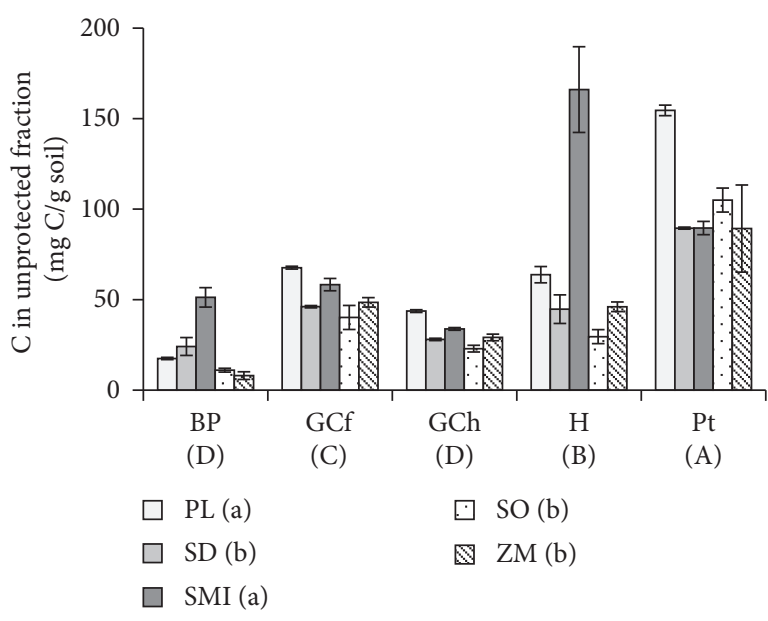

(a)

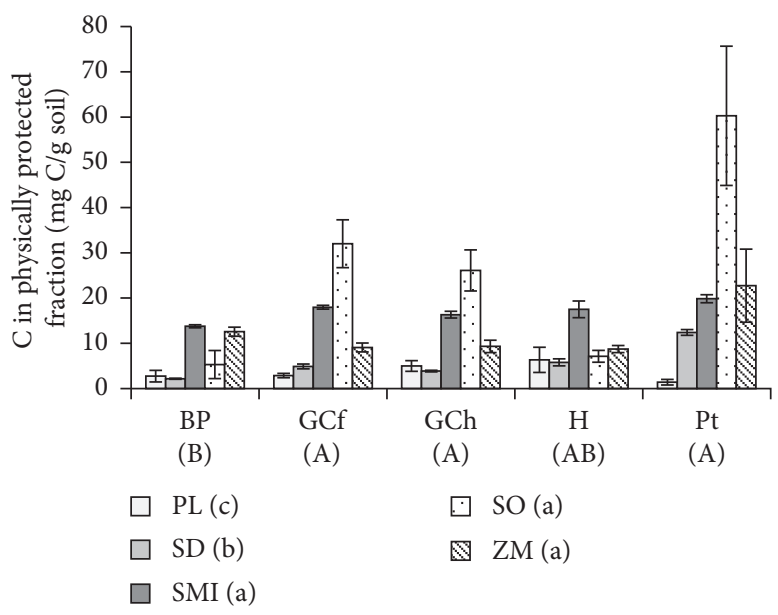

(b)

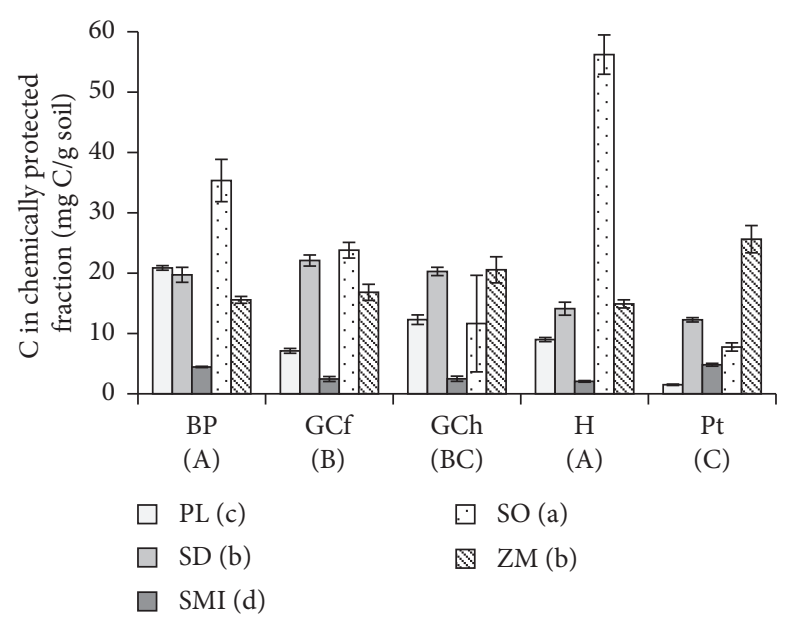

(c)

FiguRE 1: Recovery of (a) unprotected, (b) physically protected, and (c) chemically protected C using different fractionation methods for amended soils. Error bars for standard error $(n=3)$. Methods sharing the same lowercase letter and treatments sharing the same uppercase letter are not significantly different according to two-way ANOVA and Tukey's post hoc testing $(p<0.05)$. Methods: PL: Plaza et al. [18]; SD: Six et al. [9] using microaggregate isolator and density flotation; SMI: Six et al. [9] using microaggregate isolator and NaHMP for dispersion; SO: Sohi et al. [19]; ZM: Zimmermann et al. [15]. Samples: BP: bare plot control; GCf: garden compost (full rate); GCh: garden compost (half rate); H: composted horse manure; Pt: Irish peat moss.

TABLE 5: C recovered from free particulate organic matter.

\begin{tabular}{|c|c|c|c|c|}
\hline \multirow{2}{*}{ Treatment } & \multicolumn{4}{|c|}{ Method } \\
\hline & PL & $\mathrm{SO}$ & $\mathrm{ZM}$ & Mean of treatment \\
\hline $\mathrm{BP}$ & $33.4 \pm 0.1$ & $21.5 \pm 2.6$ & $22.0 \pm 5.3$ & $25.6 \pm 2.6 \mathrm{D}$ \\
\hline GCf & $73.4 \pm 2.8$ & $41.8 \pm 6.7$ & $65.2 \pm 3.0$ & $60.1 \pm 5.2 B$ \\
\hline GCh & $50.9 \pm 5.4$ & $40.2 \pm 8.7$ & $49.7 \pm 2.6$ & $46.9 \pm 3.5 \mathrm{C}$ \\
\hline $\mathrm{H}$ & $72.6 \pm 3.6$ & $31.9 \pm 4.3$ & $66.0 \pm 1.2$ & $56.8 \pm 6.5 \mathrm{BC}$ \\
\hline $\mathrm{Pt}$ & $94.2 \pm 1.8$ & $61.5 \pm 5.3$ & $62.8 \pm 10.2$ & $72.8 \pm 6.3 \mathrm{~A}$ \\
\hline Mean of method & $64.9 \pm 5.7 \mathrm{a}$ & $39.4 \pm 4.2 \mathrm{c}$ & $53.1 \pm 4.9 b$ & \\
\hline
\end{tabular}

Values are expressed as a percentage of total C recovered. Mean \pm standard error $(n=3)$. Lowercase letters in the bold values signify methods that are not significantly different, and uppercase letters signify treatments that are not significantly different according to two-way ANOVA with Tukey's post hoc testing $(p>0.05$. Method $*$ treatment interactions $p<0.01)$.

there were significant method $\times$ treatment interactions. For example, the SO method recovered high amounts of chemically protected $\mathrm{C}$ in the horse manure and bare plot control treatments, compared to other methods (Figure 1(c)).
3.5. C Concentration of Fractions. Examining the quantity of $\mathrm{C}$ in the fraction, relative to the mass of the fraction (Figure 2), reveals that the $\mathrm{C}$ concentration of the unprotected fraction obtained using the SMI size separation 
TABle 6: Aggregate OM recovery.

\begin{tabular}{|c|c|c|c|c|c|c|}
\hline \multirow{2}{*}{ Treatment } & \multicolumn{6}{|c|}{ Method } \\
\hline & PL & SD & SMI & $\mathrm{SO}$ & $\mathrm{ZM}$ & Mean of treatment \\
\hline $\mathrm{BP}$ & $15.7 \pm 2.1$ & $56.1 \pm 6.4$ & $43.6 \pm 1.8$ & $10.3 \pm 5.8$ & $34.8 \pm 3.2$ & $32.1 \pm 4.8 \mathrm{~B}$ \\
\hline GCf & $17.5 \pm 3.2$ & $69.8 \pm 1.3$ & $73.1 \pm 2.2$ & $33.4 \pm 5.5$ & $12.2 \pm 1.3$ & $41.2 \pm 7.0 \mathrm{~A}$ \\
\hline GCh & $28.9 \pm 7.0$ & $61.1 \pm 0.3$ & $79.7 \pm 1.1$ & $43.2 \pm 4.8$ & $15.6 \pm 1.3$ & $45.7 \pm 6.3 \mathrm{~A}$ \\
\hline $\mathrm{H}$ & $16.0 \pm 3.3$ & $77.2 \pm 4.2$ & $47.4 \pm 2.5$ & $7.7 \pm 1.3$ & $12.5 \pm 0.7$ & $32.2 \pm 7.2 \mathrm{~B}$ \\
\hline $\mathrm{Pt}$ & $4.9 \pm 1.8$ & $89.3 \pm 0.3$ & $62.1 \pm 1.2$ & $33.9 \pm 6.0$ & $18.0 \pm 7.0$ & $41.6 \pm 8.3 \mathrm{~A}$ \\
\hline Mean of methods & $16.6 \pm 2.5 d$ & $70.7 \pm 3.4 a$ & $61.2 \pm 3.8 b$ & $25.7 \pm 4.2 c$ & $18.6 \pm 2.6 c d$ & \\
\hline
\end{tabular}

Values are expressed as a percentage of total C recovered. Mean \pm standard error $(n=3)$. Lowercase letters in the bold values signify methods that are not significantly different, and uppercase letters signify treatments that are not significantly different according to two-way ANOVA with Tukey's post hoc testing $(p>0.05)$. Method $*$ treatment interactions $(p<0.01)$.

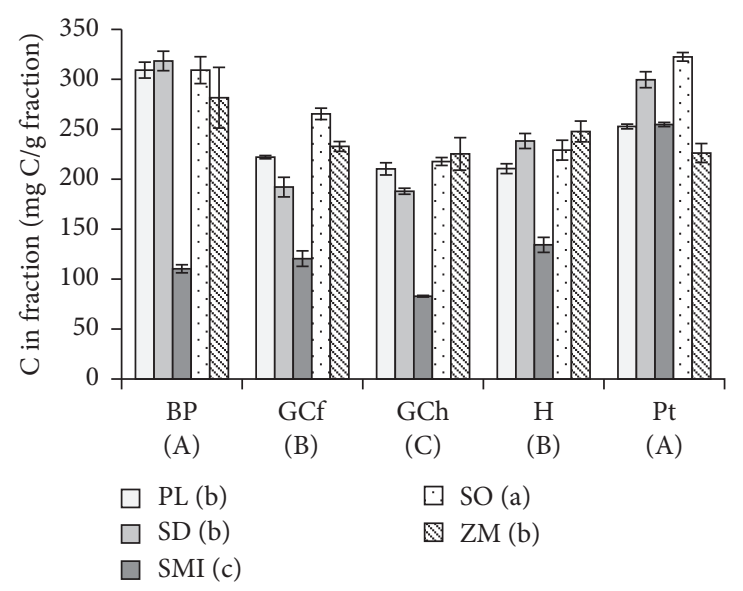

(a)

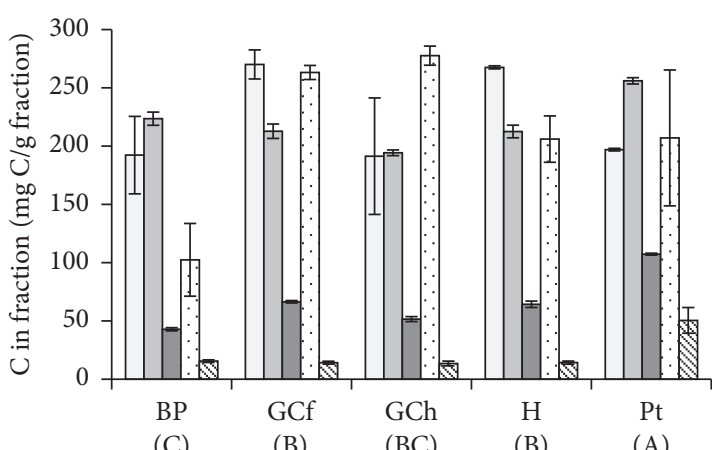

$\square$ PL (a)
$\square$ SD (a)
$\square$ SMI (b)

$\square \mathrm{SO}(\mathrm{a})$

Z ZM (c)

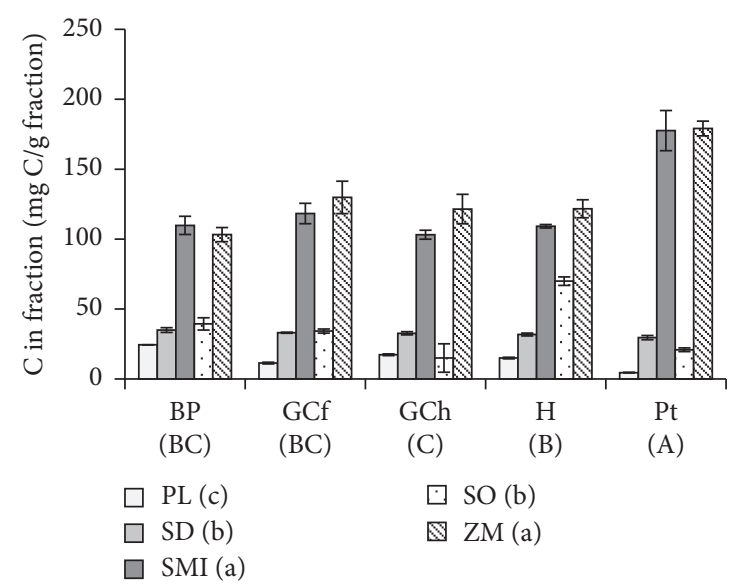

(c)

FIGURE 2: C concentration of (a) unprotected, (b) physically protected, and (c) chemically protected C fractions using different fractionation methods for amended soils. Error bars for standard error $(n=3)$. Methods sharing the same lowercase letter and treatments sharing the same uppercase letter are not significantly different according to two-way ANOVA and Tukey's post hoc testing $(p<0.05)$. Methods: PL: Plaza et al. [18]; SD: Six et al. [9] using microaggregate isolator and density flotation; SMI: Six et al. [9] using microaggregate isolator and NaHMP for dispersion; SO: Sohi et al. [19]; ZM: Zimmermann et al. [15]. Samples: BP: bare plot control; GCf: garden compost (full rate); GCh: garden compost (half rate); $\mathrm{H}$ : composted horse manure; Pt: Irish peat moss.

method is reduced compared to the other density separation methods (Figure 2(a)). The SMI and ZM methods also result in significantly lower $\mathrm{C}$ concentrations than the other three methods for physically protected C (Figure 2(b)) but elevated chemically protected C (Figure $2(\mathrm{c})$ ).

\section{Discussion}

All the fractionation methods vary in terms of notational differences (e.g., designation of macroaggregate SOC as being either unprotected or physically protected) and also 
practical methodological differences between methods (e.g., density vs. size seperation). This has led to significant differences between methods for total, unprotected, physically protected, and chemically protected C.

4.1. Total C Recovery of Methods. The two methods that recovered the most $\mathrm{C}$ in total were the SMI and SO methods. These are the only methods that do not involve density separation with SPT at any stage. The use of SPT vs. NaI is discussed later.

Sample preparation before fractionation, in terms of whether the method uses $2 \mathrm{~mm}$ sieved soil or not, may also account for SMI and SO having higher total $\mathrm{C}$ recovery. A large proportion (up to 50\%) of total C recovered in the SMI method, for example, was attributed to the large $>2000 \mu \mathrm{m}$ POM fraction (data not shown). This material will be removed during $2 \mathrm{~mm}$ sieving in sample preparation for $\mathrm{PL}$ and ZM methods before fractionation takes place. Sieving may also remove larger aggregates containing SOM. This may contribute to the lower mean $C$ recovery for the PL and ZM methods compared to the SMI and SO methods that do not sieve soil as a pretreatment. The presence of this coarse litter can make up a large proportion of organic matteramended soil samples especially in the case of soils amended with coarse compost $[20,21]$. Therefore, the decision on whether or not to sieve samples before physical fractionation will depend on the soil used (i.e., the size of the large POM fraction) and also whether the research interest is in investigating free POM in detail or is focussed on the heavier fractions. That said, the SD does not sieve the soil as a pretreatment but failed to recover more total $\mathrm{C}$ than the PL and ZM methods that do sieve.

The results presented here suggest that the higher the $\mathrm{C}$ content of the soil, the lower the total $\mathrm{C}$ recovery. Possibly, as a result (i) increased free light fraction POM in these soils, which is more easily lost; and/or (ii) higher C content soils possibly containing more DOM, which was not isolated during this trial for any of the methods. This has implications for studies looking into amended soils, particularly those which have had high volumes of exogenous organic matter inputs. This may also account for the reduced total recoveries in this trial, compared to the study by Poeplau et al. [16]. The soils used here had at least double the total C content than those used by Poeplau et al. [16].

4.2. Unprotected, Physically, and Chemically Protected C Recovery. Evidence presented here suggests that the amount of $\mathrm{C}$ recovered in each of the conceptual pools by a given method depends on both notational differences between methods, and also practical methodological differences between methods, such as aggregate dispersion and density vs. size separation.

However, it is important to consider that each of the five methods have a number of operational differences, which makes drawing firm conclusions difficult. For example, when considering density separation, which is applied initially in three methods (PL, SO, and ZM). These three methods use different density fluids (SPT and NaI) and at different densities $\left(1.80\right.$ or $\left.1.85 \mathrm{~g} \cdot \mathrm{cm}^{-3}\right)$. In addition, the methods that use SPT (PL and ZM) also apply sieving before the density separation. Therefore, it is possible that the higher amounts of unprotected free POM obtained by the PL and ZM methods may have more than one explanation.

4.2.1. Notational Differences in Methods. As discussed previously, some methods distinguish between macroaggregates and microaggregates (e.g., PL, SD, and SMI), and some group all aggregate size fractions together (SO and $\mathrm{ZM}$ ). In the latter case, all intra-aggregate light or particulate $\mathrm{OM}$ is classed as physically protected. However, in the former, the OM contained within macroaggregates is classed as unprotected, and only OM occluded in microaggregates is classed as physically protected. The addition of OM from macroaggregates to the unprotected pool may account for the significantly $(p<0.05)$ greater proportion of unprotected $C$ reported by the PL and SMI methods when compared to the SO and ZM methods. This in turn leads to a reduction in physically protected $\mathrm{C}$ in methods that classify macroaggregate $\mathrm{C}$ as unprotected rather than physically protected. The PL and SD methods, for example, have among the lowest soil concentrations of physically protected $\mathrm{C}$ and among the highest concentrations of unprotected $\mathrm{C}$ (Figure 1), and the reverse is true for the SO method and $\mathrm{ZM}$ method.

However, despite the SMI and SD methods making the same distinction between microaggregates and macroaggregates as the PL method, the SD method did not isolate significantly more unprotected $\mathrm{C}$ than the $\mathrm{SO}$ and $\mathrm{ZM}$ methods, and the SMI method did not isolate significantly less physically protected $\mathrm{C}$ than the SO and ZM methods. Therefore, there are also practical methodological differences between methods that need to be considered, such as aggregate dispersion technique, and whether the method uses size or density separation (see below).

When all aggregate fractions are grouped together regardless of size class, it can be seen that the SD and SMI methods isolate more aggregate $C$ than the other three methods. Neither of these methods involves an initial density separation to isolate free (unoccluded) POM before dispersing the aggregates. Therefore, the aggregate OM that is isolated in these methods consists of both the intra-aggregate OM and the free POM that is of the same size class as the aggregates.

4.2.2. Aggregate Dispersion. Of the three methods that include macroaggregate $\mathrm{OM}$ in the unprotected $\mathrm{C}$ pool (PL, $\mathrm{SD}$, and SMI), the SD method resulted in significantly less unprotected $\mathrm{C}$ being isolated. An explanation for this might relate to the technique used to disperse OM contained within macroaggregates, which differed between SD (use of a vacuum) and SMI and PL (microaggregate isolation via wet sieving) (Table 2). The vacuum method may not be as aggressive in breaking up of macroaggregates compared to the microaggregate isolator, resulting in less OM being liberated from the macroaggregate fraction. This potentially less aggressive break up of aggregates in the SD method may also account for the SD recovering more chemically protected $\mathrm{C}$ 
than the SMI and PL method to compensate for less intraaggregate OM being dispersed.

4.2.3. Density Separation. Four of the five methods in this trial use density separation at some stage in the fractionation procedure ( $\mathrm{PL}, \mathrm{SD}, \mathrm{SO}$, and $\mathrm{ZM}$ ). However, as previously discussed, because the SD method has an initial size separation, it is difficult to distinguish between intra-aggregate $\mathrm{OM}$ and free $\mathrm{OM}$ of the same size class. The remaining three methods (PL, SO, and ZM) involve an initial density separation of free POM (i.e., POM not associated with aggregates or mineral components). The majority of density fractionation methods use either sodium polytungstate (SPT) or sodium iodide (NaI) as density solutions, because they are less toxic than halogenated hydrocarbons previously used in fractionation methods [22]. Sequeira et al. [23] reported that they found no difference in $C$ recovery in the free light fraction when comparing SPT and NaI density fluids, but here, SPT (PL and ZM) recovered significantly more free POM than the SO method, which uses NaI. The methods that use SPT (PL and ZM) also involve sieving as a pretreatment, unlike the SO method (discussed above). Therefore, the act of sieving could be releasing free POM from large aggregates, leading to elevated unprotected $\mathrm{C}$, and not be related to whether SPT of NaI is used as a density fluid. In turn, this will result in the reduced aggregate OM released in the PL and $\mathrm{ZM}$ methods compared to the SO method.

The PL method, which uses a higher density of SPT $\left(1.85 \mathrm{~g} \cdot \mathrm{cm}^{-3}\right)$ than the ZM method $\left(1.80 \mathrm{~g} \cdot \mathrm{cm}^{-3}\right)$, also recovered significantly more free POM than the ZM method. This increase in free POM with increasing density of fluid is in concordance with the findings of Sequeira et al. [23].

During physical fractionation, the chemically protected fraction can be isolated using either density separation (PL, $\mathrm{SD}, \mathrm{SO}$, and ZM) or size separation (SMI). The SMI method isolates significantly less chemically protected $C$ than the other four methods, suggesting that a density-based approach isolates more chemically protected $\mathrm{C}$ than a sizebased approach. In the density-based approaches, the recovery of chemically protected $\mathrm{C}$ was significantly higher in the SO method, which uses NaI, rather than SPT, as a density fluid. Within the methods that use SPT as a density fluid (PL, $\mathrm{SD}$, and $\mathrm{ZM})$, the $\mathrm{ZM}\left(1.80 \mathrm{~g} \cdot \mathrm{cm}^{-3} \mathrm{SPT}\right)$ recovers significantly more than the PL method $\left(1.85 \mathrm{~g} \cdot \mathrm{cm}^{-3}\right)$, reverse of the free POM (discussed above).

4.3. Fractionation for Amended Soils. Total C recovery was negatively affected by application of the high $\mathrm{C}$ content peat amendment. This will have implications for the use of physical fractionation techniques in assessing the effects of high $\mathrm{C}$ soil amendments on $\mathrm{C}$ stabilisation. In addition, for all analysis (total, unprotected, physically, and chemically protected $C)$, there were significant method $\times$ treatment interactions $(p<0.05)$, meaning that different methods were more effective at isolating certain $\mathrm{C}$ conceptual pools than others, for certain amendments. This will have implications for studies investigating amendment application on $\mathrm{C}$ stabilisation, as this work suggests that the performance of each method varies depending on the amendment in question. This highlights the need for an understanding of the nature of experimental samples and the stabilisation mechanism of most interest, both prior to method selection and when comparing results between studies.

4.4. Practical Considerations for Method Selection. The physical fractionation method selection had a significant impact on the total $\mathrm{C}$ recovered (Table 4) and the distribution of the recovered $\mathrm{C}$ between conceptual pools that are defined based on current ideas on the importance of aggregate occlusion and mineral association in controlling organic C persistence in soil (Figure 1). These betweenmethod differences most likely resulted from variation in both the methodological fractions obtained (e.g., distinguishing aggregate size classes or not) and their subsequent designation to conceptual pools (protected versus unprotected) and the procedures used in sample pretreatment and subsequent aggregate dispersion and fractionation steps. An appreciation of the sensitivity to methodological variation of the characterization of soil $\mathrm{C}$ to conceptual pools is vital to the interpretation of data produced by physical fractionation methods. However, the scientific value of the fractions will not be the only consideration for researchers when selecting an appropriate fractionation method. Factors such as the objectives of the individual study versus logistics, time, and budget will also play a part. The number of fractions obtained for each method varies greatly (Table 3 ) and retrieval of each of these fractions takes time, and indeed could potentially lead to greater losses of $\mathrm{C}$ as the methods become more complex (Table 4). Therefore, when selecting a fractionation method, the researcher will need to consider their individual research needs, in terms of the information they require from each fraction, and weigh this against the time it will take to obtain these fractions.

Dissolved organic matter (DOM) is often overlooked in organic matter fractionation methods but literature suggests that this should not be the case. Despite contributing only a small proportion of total soil C, DOM is a reactive fraction of SOM [24] and is an important source of C for soil microorganisms [25]. In fact, the availability of DOM for breakdown by the microbial community is considered vital for soil $\mathrm{C}$ turnover as microbial uptake occurs from the solution phase [26].

All the methods in this study define a mineral fraction, reflecting the importance in current thinking $[2,16]$ of association of $\mathrm{C}$ with mineral surfaces via sorption and complexation for $\mathrm{C}$ stabilisation. How the mineral fraction is defined, particularly in which fraction sand is present, impacts on the quality of $\mathrm{C}$ obtained in all the fractions. This will have implications if analysing soils with a high sand content, or comparing multiple sites with different soil textures. The presence or absence of sand in the fraction, which is thought to only have weak associations with C [22], could, in essence, dilute the sample by increasing the mass of the fraction without contributing much $\mathrm{C}$. 
All methods recognise the importance of occlusion in aggregates as a mechanism for stabilising $\mathrm{C}$ in soils. However, not all methods define microaggregate and macroaggregate occluded $\mathrm{C}$ independently. It is thought that organic matter is protected from decomposition to a greater extent in microaggregates than in macroaggregates, not only as a result of reduced microbial access to organic $\mathrm{C}$ substrates due to the smaller and less connected soil pores, but also as a result of slower decomposition in response to greater prevalence of anoxic conditions due to slower oxygen diffusion through small water-filled pores [27]. Microaggregates are also tightly held together by stronger internal binding agents, which results in them being more stable in the soil system, and providing better long-term protection for SOM [25]. Occlusion within microaggregates, contained within macroaggregates, has been suggested to be the most important for C stabilisation in managed sites $[28,29]$ as well as influencing the composition of the microbial community [30].

Aggregate isolation methods, such as SD and SMI proposed by Six et al. [9], allow for significance of their size, in the protection of SOM in soil to be determined [31], but uniquely they also quantify silt and clay contained within the aggregate. This could be of particular interest as $\mathrm{C}$ associated with silt and clay, contained within an aggregate, could be both chemically and physically protected. This information would be valuable in testing hypotheses about the cycling of C within aggregate formation-stabilisation-destruction processes and develop understanding of an overlooked pool of organic matter that is governed by multiple protection mechanisms. However, as previously discussed, retrieval of multiple fractions does not come without costs, and is not always possible in the case of soils that have a high proportion of POM. When the mass of POM constitutes a large proportion of the mass of the total soil sample, as it did for the amended soil samples under investigation here, there is often insufficient residual sample for separation into the remaining fractions. Therefore, in order to ensure that enough material is left in fractions towards the end of the process, larger volumes of soil will need to be processed, increasing analytical time and cost.

A number of factors during size separation processes, such as wet sieving, can affect the results, including sieve size, speed, and duration, which will need to be taken into account [12], particularly when wet sieving by hand as there will be obvious differences between operators. In addition, sieving to separate aggregate size classes will also separate out POM of different size classes along with sand particles [32], which do not contain occluded OM from the aggregate and may impact on results. It is thought that wet sieving may also lead to leaching of DOC to smaller aggregate size classes, along with high energy slaking procedures breaking up weaker aggregates and redistributing fine particles into smaller aggregate size classes [33].

The majority of density fractionation methods use either sodium polytungstate (SPT) or sodium iodide $(\mathrm{NaI})$ as density solutions, because they are less toxic than halogenated hydrocarbons previously used in fractionation methods [22]. Although the findings of this study are inconclusive as to which solution is more appropriate, according to Sequeira et al. [23], the decision of whether to use SPT or NaI as a density solution is dependent on the following factors: (i) Cost (NaI is cheaper than SPT); (ii) health and safety (SPT is less toxic than NaI); and (iii) density range (SPT can produce a wider range of densities, whilst maintaining a lower viscosity at higher concentrations) [34].

There are also additional considerations if the intention is to produce fractions that can be further analysed, for example by nuclear magnetic resonance (NMR) and isotopic tracers, to further explore the composition and residence time within each fraction. For example, problems may arise for cross-polarization spectra in NMR if the C content of the

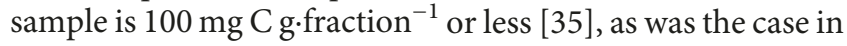
the current study for: unprotected $\mathrm{C}$ isolated using the SMI method; physically protected $\mathrm{C}$ using the SMI and ZM methods; and chemically protected $\mathrm{C}$ isolated using the PL, $\mathrm{SD}$, and SO methods (Figure 2). Differences in fraction C concentrations are determined by the presence or absence of mineral components (particularly sand in our case), in different fractions depending on the fractionation method. For example, using size separation techniques to isolate unprotected $\mathrm{C}$ in the SMI method means that mineral components within the same size class, such as sand and gravel, which would sink in a density separation method, are included in the POM fraction. The inclusion of sand in the aggregate fraction in the SMI and ZM methods (Table 2) also results in a significantly reduced $\mathrm{C}$ concentration in the physically protected fraction compared to the other methods, but higher chemically protected C. Poor NMR spectra often result from low sample $\mathrm{C}$ concentrations due to background signal caused by rotor cap and probe components, in addition to broad peaks and low signal-noise ratios [35]. Samples that are low in organic molecules, therefore, may require pretreatment with hydrofluoric acid $(\mathrm{HF})$, to dissolve minerals thereby concentrating organic matter signals [36]. However, the use of HF has associated health and safety concerns, and takes time. Treating samples with $\mathrm{HF}$ has also been observed to cause problems as it can lead to loss of SOC in some soils [37].

It is also important to note that if it is the intention to combine physical fractionation techniques with microbial analyses, it may not be suitable to use density fractionation at all because density solutions may be detrimental to microbial activity [38] or isolation and analysis of nucleic acid markers for microbial community characterization.

\section{Conclusions}

For the five physical fractionation methods tested here [18]; $[15,19]$; and two variants of [9], the choice of method had a significant impact on the distribution of organic $C$ between fractions that conceptually are representative of unprotected, chemically protected, and physically protected pools. This between-method variation can be interpreted in terms of differences in: (i) the methodological fractions obtained; (ii) the subsequent subjective designation of fractions to conceptual pools; and, (iii) procedures used in 
sample pretreatment and subsequent aggregate dispersion and fractionation steps.

Our method comparison highlights the need for an understanding of the nature of the samples under investigation, particularly for amended soil. In addition, an appreciation for the stabilisation mechanism(s) under study and operational differences between methods when selecting a method to address a particular research question is needed. In the case of cross-study comparisons of soil C quality data, there will be implications if data have been obtained using differing physical fractionation methods.

Future work could examine the various steps of fractionation methods and whether the fractions from soils with exogenous organic matter inputs isolated do indeed have turnover times that are consistent with the conceptual pools they are intended to represent (as in [16]).

\section{Data Availability}

The data used to support the findings of this study are available from the corresponding author upon request.

\section{Conflicts of Interest}

The authors declare that they have no conflicts of interest.

\section{Acknowledgments}

This research was supported by an industrial Co-Operative Award in Science and Engineering (CASE), jointly funded by the Biotechnology and Biological Sciences Research Council (BBSRC), the Royal Horticultural Society (RHS), and the Department for Environment, Food and Rural Affairs (Defra).

\section{References}

[1] S. Ghosh, B. Wilson, S. Ghoshal, N. Senapati, and B. Mandal, "Organic amendments influence soil quality and carbon sequestration in the Indo-Gangetic plains of India," Agriculture, Ecosystems \& Environment, vol. 156, pp. 134-141, 2012.

[2] M. W. I. Schmidt, M. S. Torn, S. Abiven et al., "Persistence of soil organic matter as an ecosystem property," Nature, vol. 478, no. 7367, pp. 49-56, 2011.

[3] J. Leifeld and I. Kögel-Knabner, "Soil organic matter fractions as early indicators for carbon stock changes under different land-use?," Geoderma, vol. 124, no. 1-2, pp. 143-155, 2005.

[4] B. Minasny, B. P. Malone, A. B. McBratney et al., "Soil carbon 4 per mille," Geoderma, vol. 292, pp. 59-86, 2017.

[5] D. L. D. Lima, S. M. Santos, H. W. Scherer et al., "Effects of organic and inorganic amendments on soil organic matter properties," Geoderma, vol. 150, no. 1-2, pp. 38-45, 2009.

[6] E. Medina, C. Paredes, M. A. Bustamante, R. Moral, and J. Moreno-Caselles, "Relationships between soil physicochemical, chemical and biological properties in a soil amended with spent mushroom substrate," Geoderma, vol. 173-174, pp. 152-161, 2012.

[7] R. Ryals, M. Kaiser, M. S. Torn, A. A. Berhe, and W. L. Silver, "Impacts of organic matter amendments on carbon and nitrogen dynamics in grassland soils," Soil Biology and Biochemistry, vol. 68, pp. 52-61, 2014.
[8] D. Courtier-Murias, A. J. Simpson, C. Marzadori et al., "Unraveling the long-term stabilization mechanisms of organic materials in soils by physical fractionation and NMR spectroscopy," Agriculture, Ecosystems \& Environment, vol. 171, pp. 9-18, 2013.

[9] J. Six, R. T. Conant, E. A. Paul, and K. Paustian, "Stabilization mechanisms of soil organic matter: implications for C-saturation of soils," Plant and Soil, vol. 241, no. 2, pp. 155-176, 2002.

[10] B. John, T. Yamashita, B. Ludwig, and H. Flessa, "Storage of organic carbon in aggregate and density fractions of silty soils under different types of land use," Geoderma, vol. 128, no. 1-2, pp. 63-79, 2005.

[11] M. V. Lutzow, I. Kogel-Knabner, K. Ekschmitt et al., "Stabilization of organic matter in temperate soils: mechanisms and their relevance under different soil conditions-a review," European Journal of Soil Science, vol. 57, no. 4, pp. 426-445, 2006.

[12] D. C. Olk and E. G. Gregorich, "Overview of the symposium proceedings, "meaningful pools in determining soil carbon and nitrogen dynamics"," Soil Science Society of America Journal, vol. 70, no. 3, pp. 967-974, 2006.

[13] C. A. Creamer, T. R. Filley, and T. W. Boutton, "Long-term incubations of size and density separated soil fractions to inform soil organic carbon decay dynamics," Soil Biology and Biochemistry, vol. 57, pp. 496-503, 2013.

[14] R. Jandl, M. Rodeghiero, C. Martinez et al., "Current status, uncertainty and future needs in soil organic carbon monitoring," Science of The Total Environment, vol. 468-469, pp. 376-383, 2014.

[15] M. Zimmermann, J. Leifeld, M. W. I. Schmidt, P. Smith, and J. Fuhrer, "Measured soil organic matter fractions can be related to pools in the RothC model," European Journal of Soil Science, vol. 58, no. 3, pp. 658-667, 2007.

[16] C. Poeplau, A. Don, J. Six et al., "Isolating organic carbon fractions with varying turnover rates in temperate agricultural soils-a comprehensive method comparison," Soil Biology and Biochemistry, vol. 125, pp. 10-26, 2018.

[17] P. D. Alexander and I. M. Nevison, "The long-term effects of repeated application of the same organic material to soil in a horticultural context," Acta Horticulturae, vol. 1076, no. 1076, pp. 143-150, 2015.

[18] C. Plaza, D. Courtier-Murias, J. M. Fernández, A. Polo, and A. J. Simpson, "Physical, chemical, and biochemical mechanisms of soil organic matter stabilization under conservation tillage systems: a central role for microbes and microbial byproducts in C sequestration," Soil Biology and Biochemistry, vol. 57, pp. 124-134, 2013.

[19] S. P. Sohi, N. Mahieu, J. R. M. Arah, D. S. Powlson, B. Madari, and J. L. Gaunt, "A procedure for isolating soil organic matter fractions suitable for modeling," Soil Science Society of America Journal, vol. 65, no. 4, pp. 1121-1128, 2001.

[20] M. González, E. Gomez, R. Comese, M. Quesada, and M. Conti, "Influence of organic amendments on soil quality potential indicators in an urban horticultural system," Bioresource Technology, vol. 101, no. 22, pp. 8897-8901, 2010.

[21] B. L. M. Leroy, H. M. S. K. Herath, S. Sleutel et al., "The quality of exogenous organic matter: short-term effects on soil physical properties and soil organic matter fractions," Soil Use and Management, vol. 24, no. 2, pp. 139-147, 2008.

[22] M. von Lützow, I. Kögel-Knabner, K. Ekschmitt et al., "SOM fractionation methods: relevance to functional pools and to stabilization mechanisms," Soil Biology and Biochemistry, vol. 39, no. 9, pp. 2183-2207, 2007. 
[23] C. H. Sequeira, M. M. Alley, and B. P. Jones, "Evaluation of potentially labile soil organic carbon and nitrogen fractionation procedures," Soil Biology and Biochemistry, vol. 43, no. 2, pp. 438-444, 2011.

[24] I. De Troyer, F. Amery, C. Van Moorleghem, E. Smolders, and R. Merckx, "Tracing the source and fate of dissolved organic matter in soil after incorporation of a 13C labelled residue: a batch incubation study," Soil Biology and Biochemistry, vol. 43, no. 3, pp. 513-519, 2011.

[25] E. G. Gregorich, M. H. Beare, U. Stoklas, and P. St-Georges, "Biodegradability of soluble organic matter in maize-cropped soils," Geoderma, vol. 113, no. 3-4, pp. 237-252, 2003.

[26] B. Marschner and K. Kalbitz, "Controls of bioavailability and biodegradability of dissolved organic matter in soils," Geoderma, vol. 113, no. 3-4, pp. 211-235, 2003.

[27] S. M. F. Rabbi, H. Daniel, P. V. Lockwood et al., "Physical soil architectural traits are functionally linked to carbon decomposition and bacterial diversity," Scientific Reports, vol. 6, no. 1, pp. 1-9, 2016

[28] A. Y. Y. Kong, J. Six, D. C. Bryant, R. F. Denison, and C. van Kessel, "The relationship between carbon input, aggregation, and soil organic carbon stabilization in sustainable cropping systems," Soil Science Society of America Journal, vol. 69, no. 4, pp. 1078-1085, 2005.

[29] J. Six and K. Paustian, "Aggregate-associated soil organic matter as an ecosystem property and a measurement tool," Soil Biol. Biochem.vol. 68, pp. A4-A9, 2014.

[30] J. Six, H. Bossuyt, S. Degryze, and K. Denef, "A history of research on the link between (micro)aggregates, soil biota, and soil organic matter dynamics," Soil and Tillage Research, vol. 79, no. 1, pp. 7-31, 2004.

[31] H. Bossuyt, J. Six, and P. F. Hendrix, "Protection of soil carbon by microaggregates within earthworm casts," Soil Biology and Biochemistry, vol. 37, no. 2, pp. 251-258, 2005.

[32] Y. He, C. Chen, Z. Xu, D. Williams, and J. Xu, "Assessing management impacts on soil organic matter quality in subtropical Australian forests using physical and chemical fractionation as well as 13C NMR spectroscopy," Soil Biology and Biochemistry, vol. 41, no. 3, pp. 640-650, 2009.

[33] A. Gunina and Y. Kuzyakov, "Pathways of litter C by formation of aggregates and SOM density fractions: implications from 13C natural abundance," Soil Biology and Biochemistry, vol. 71, pp. 95-104, 2014.

[34] J. Six, P. A. Schultz, J. D. Jastrow, and R. Merckx, "Recycling of sodium polytungstate used in soil organic matter studies," Soil Biology and Biochemistry, vol. 31, no. 8, pp. 1193-1196, 1999.

[35] C. M. Preston, "Carbon-13 solid-state NMR of soil organic matter - using the technique effectively," Canadian Journal of Soil Science, vol. 81, no. 3, pp. 255-270, 2001.

[36] A. J. Simpson, M. J. Simpson, and R. Soong, "Nuclear magnetic resonance spectroscopy and its key role in environmental research," Environmental Science \& Technology, vol. 46, no. 21, pp. 11488-11496, 2012.

[37] C. Rumpel, I. Kögel-Knabner, and F. Bruhn, "Vertical distribution, age, and chemical composition of organic carbon in two forest soils of different pedogenesis," Organic Geochemistry, vol. 33, no. 10, pp. 1131-1142, 2002.

[38] C. W. Mueller, M. Gutsch, K. Kothieringer et al., "Bioavailability and isotopic composition of $\mathrm{CO} 2$ released from incubated soil organic matter fractions," Soil Biology and Biochemistry, vol. 69, pp. 168-178, 2014. 

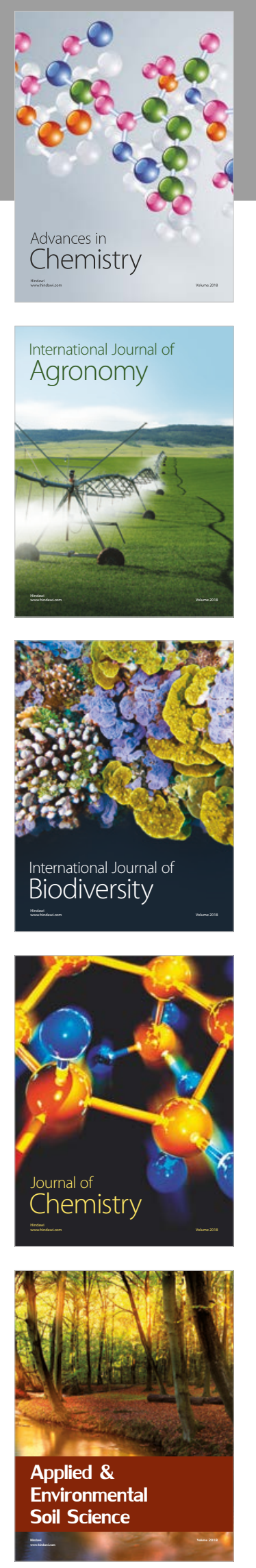

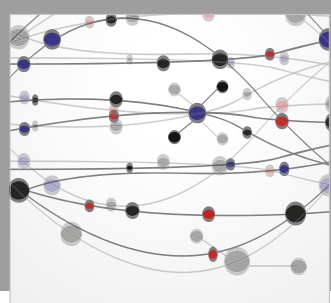

The Scientific World Journal

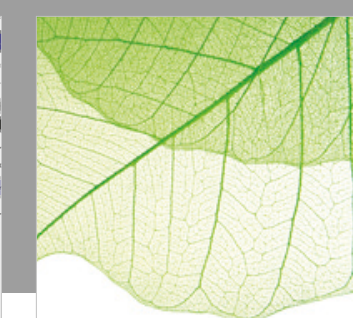

Journal of Botany

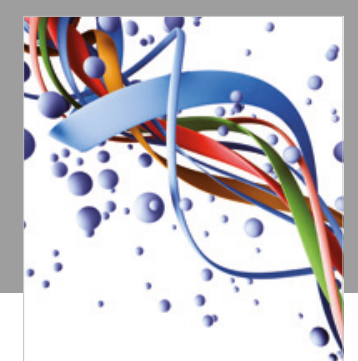

Scientifica

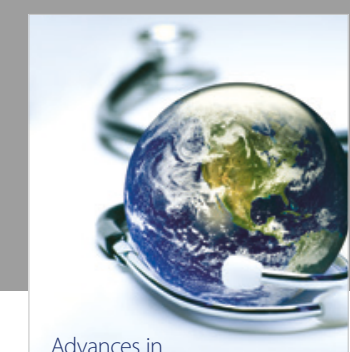

Public Health

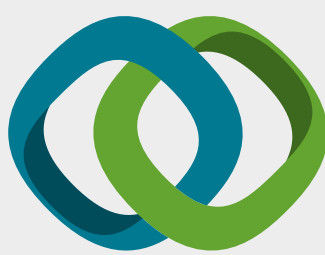

Hindawi

Submit your manuscripts at

www.hindawi.com
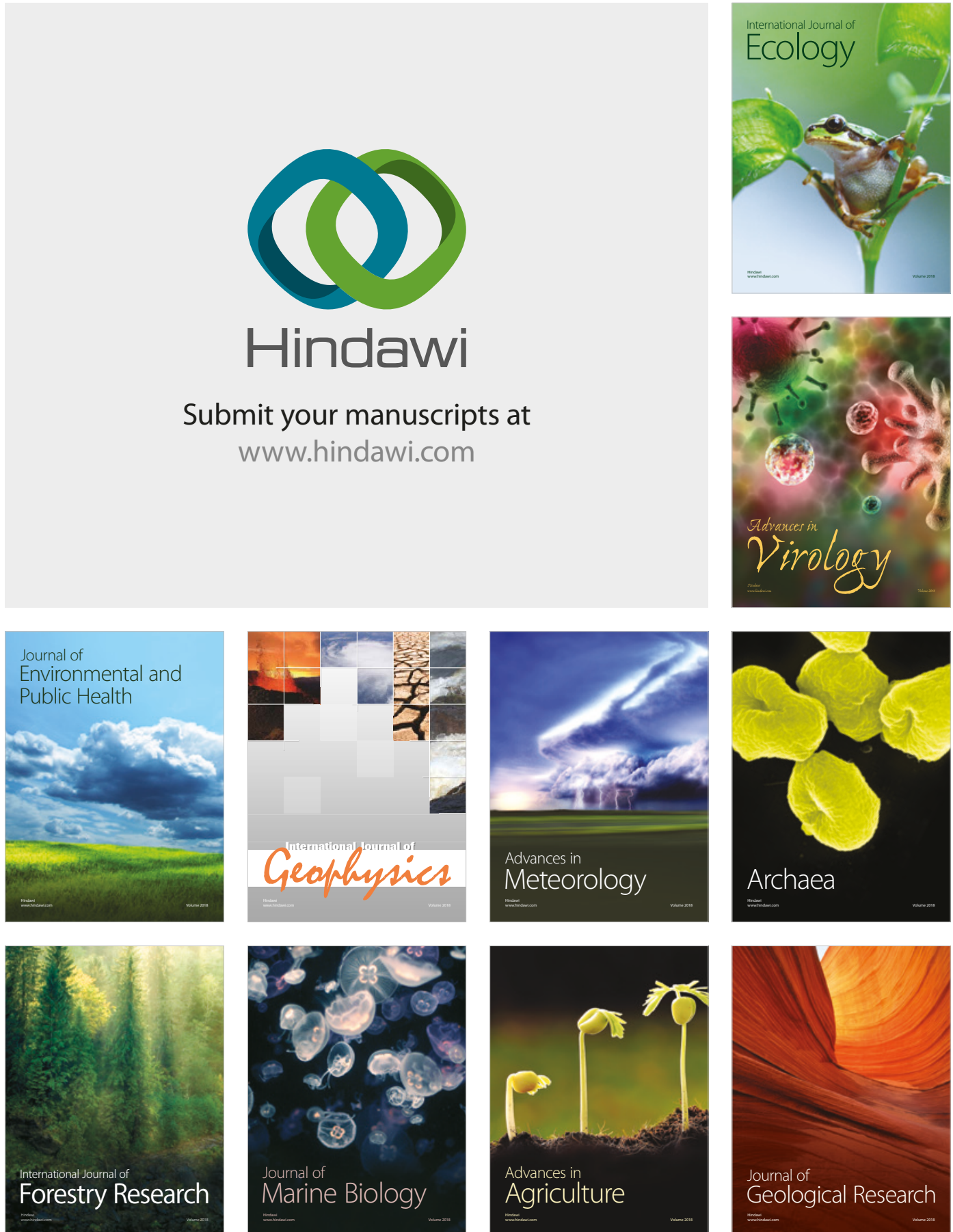

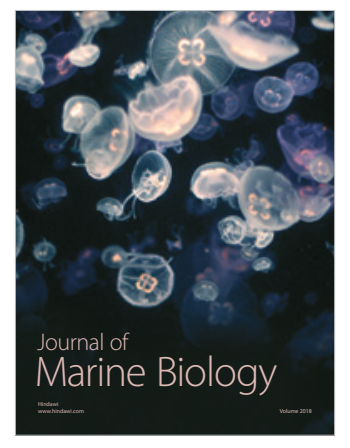

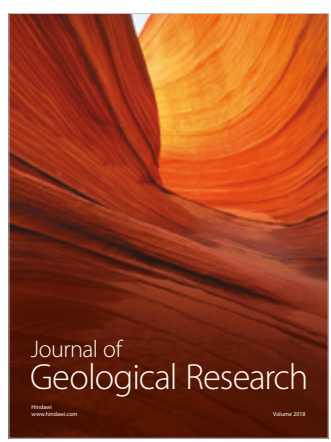

